\title{
Investigating the Extent to Which Children Use Mobile Phone Application Stores
}

\author{
Brendan Cassidy \\ University of Central Lancashire \\ Preston, UK. \\ BCassidy1@uclan.ac.uk
}

\author{
Claire Louise Haywood \\ University of Central Lancashire \\ Preston, UK. \\ CLHaywood@uclan.ac.uk
}

\author{
Gavin Sim \\ University of Central Lancashire \\ Preston, UK. \\ grsim@uclan.ac.uk
}

\begin{abstract}
This paper reports the results of a short survey aimed at examining the extent to which children use mobile phone application stores. Aspects investigated included whether children used application stores on their own or parents' devices, how children use application stores and whether they think app stores could be improved. The key contribution of this paper is the provision of evidence that children are prolific users of smart phone application stores, children are using both their parents phones and their own phones to access app stores and over half the children who download games do so at a rate of 1-2 per week. The paper also looks at how children choose the games they do on the app store and their view on how easy it is to find their chosen game. Over half the children who download games do so either having played the game before or on the recommendation of a friend. The findings raise issues about the design of app store interfaces / information architectures and whether or not children should be considered in the design of future app store interfaces.
\end{abstract}

Children. Mobile Phones. App Store. Smartphones. Games. Categorization.

\section{INTRODUCTION}

It is known that mobile technologies are now an integrated part of children's lives and children are increasingly using mobile phones at a younger age (Druin et al, 2011). Children aged between 3 \& 13 were one of the largest new user groups of mobile technologies for information access and interactivity (Roberts \& Foehr, 2008). From recent news headlines in the UK (BBC, 2013) and lawsuits internationally (ThomsonReuters, 2011) it is also known that children are using mobile phone application stores to download software such as games and activate in-app purchases.

This type of usage often accidentally incurs unwanted fees for the bill payer. What is not known is to what extent this takes place amongst children in the UK, to what extent children are using application stores independently, how they browse for games/applications in the app store and whether they do this on their own or on their parents device. Studying how children use app stores can raise important issues about how they should be designed to offer better support for children and whether or not more safeguards should be put in place to stop accidental purchases or misuse.

This paper aims to investigate this in order to provide a grounding for the further investigation into how app store interfaces should be designed and presented to children.

\section{BACKGROUND \& RELATED WORK}

It is accepted by the Child-Computer Interaction community that children are now common users of mobile technologies (Druin et al, 2011). A survey prior to the proliferation of touch screen smart phones has shown that ownership of mobile phones in Hungary in 2007 amongst children aged 9 and 10 was $76 \%$ (Mezei, Benyi \& Muller, 2007). Since the launch of the iPhone in 2007 a number of manufacturers have released their own touch screen smartphones and such phones, with their own application stores, have become commonplace amongst adults. Child specific features are now also integrated into some smartphone operating systems to protect against unwanted purchases and the opening of inappropriate applications when sharing their mobile phone with their children, for example, to play games. The 'Kid's Corner' feature on Microsoft Windows Phone 8 operating system is an example of this and allows the child to have a separate custom home screen on their parent's device. A survey by the Kaiser Family Foundation published in 2010 (Rideout, Foehr \& Roberts, 2010) has shown that $31 \%$ of children between the ages of 8 and 10 in the US own a mobile phone. This was 
compared to $21 \%$ in 2004 . So while there is evidence the number of children using mobile phones is growing, there is little literature available investigating what proportion of pre-teen children now use smart phones capable of accessing application stores, and how these are being used.

If the number of children using application stores is significant, then it makes sense that we should be recognising children as users of app stores and considering their unique needs and wants in their design. Children categorise things differently to adults (Denney \& Ziobrowski, 1972) and this has been seen with both books (Hutchinson, Druin \& Bederson, 2007) and the categorisation of games within app stores themselves (Cassidy, Antani \& Read, 2013). It was found children categorise games more in line with the characters in the game, what the character does within the game or the end goals of the game itself.

There is a clear mis-match here between the more abstract categories currently seen in app stores and the categories that make sense to children. Developmental psychology research suggests that although children are able to apply logic appropriately between the ages of 7 and 12 they are not yet able to fully understand abstract concepts (Piaget \& Inhelder, 1973). Research is needed to establish to what extent children are using application stores and how these are being used. Knowledge of this may provide a motivation for app stores to consider children in the design of game classifications and how children browse/search these stores. Knowledge of how children use application stores could also help highlight any potential problems relating to unwanted usage/purchases.

\section{METHOD}

A Survey based approach was taken consisting mainly of closed questions. Children were directly approached as it is now believed proxy reporting of technology use for children is no longer desirable and if possible data should be collected from the children themselves (Borgers, De Lew \& Hox, 2000). Designing surveys for children can be complex as there is an increased risk of satisficing when children are giving answers to researchers. As well as including closed questions, the 'Smileyometer' of the 'Fun Toolkit' (Read, 2008) was used for presenting likert scale questions to children.

\subsection{The Questionnaire}

In order to maintain the motivation of the child and keep the child's attention, a short 8 question survey was produced. The main aims of the survey were to establish to what extent do children use mobile phone application stores to play games and if children do use app stores, how are they used and how could they be improved. The questions and possible answers produced were:

- Q1: Do you ever play games on a touch screen mobile phone? [Yes, No]

- Q2: Do you download games to your own or your parent's mobile phone? [Own, Parents, Both]

- Q3: How many games do you put on your mobile phone a week? [1-2 per week, 3-5 per week, 6-8 per week, other]

- Q4: Do your parents help you download games? [Yes, No, Sometimes]

- Q5: How often do you play Mobile games? [Every day, Every week, Every month, Never]

- Q6: Tick the statement below that best describes why you choose the games you do [I have played it before, My friend told me about it, I just found it, My Mum or Dad chose it, I read about it, Other]

- Q7: How easy is it to find the game you want straight away? [Really easy, Easy, Ok, Hard, Really hard]

- Q8: What would make it easier for you to find the game you want? [Open question]

\subsection{Participants}

A total of 43 UK primary school children aged between 8 and 10 took part in the study (22 male, 21 female). The children were selected from two separate classes (ages 8-9 and ages 9-10) of the same state school. Children in this age bracket were chosen as they have been previously identified as being in the middle of one of the fastest growing user groups of mobile phones (Roberts \& Foehr, 2008).

\subsection{Procedure}

At the start of the session the teacher introduced the researcher to the class and explained that a survey was being conducted and the child could choose not to take part at any time. Following this, participants completed the survey individually in a quiet room in their school. The researcher was present to answer any questions for the duration of the process.

The children were given the survey and the purpose of the research was explained to them. Children were reminded that they did not need to take part in the study and that they could leave at any time.

Children who answered 'no' to Q1 (Do you ever play games on a touch screen mobile phone?) were told they did not need to complete the rest of the survey and could re-join their class. 


\section{RESULTS}

All 43 children approached decided to take part in the survey. 6 of these $(14 \%)$ reported that they did not play games on a mobile phone and were not asked to complete the rest of the study.

\subsection{Main Results}

$43 \%$ of the remaining 37 children surveyed used only their parents phone to play games, with $35 \%$ of children using their own smart phone and $22 \%$ using both their own and their parents phone. Table 1 illustrates.

Table 1: Q2: Do you download games to your own or your parent's mobile phone?

\begin{tabular}{|l|l|l|}
\hline \multicolumn{1}{|c|}{ Device } & \multicolumn{1}{c|}{ No. } & \multicolumn{1}{c|}{$\%$} \\
\hline Parents & 16 & $43 \%$ \\
\hline Own & 13 & $35 \%$ \\
\hline Both & 8 & $22 \%$ \\
\hline
\end{tabular}

The majority of children downloaded apps to a smartphone at a rate of 1-2 per week. Table 2 provides details.

Table 2: Q3: App download rate (per week)

\begin{tabular}{|l|l|l|}
\hline \multicolumn{1}{|c|}{ Frequency } & \multicolumn{1}{c|}{ No. } & \multicolumn{1}{c|}{$\%$} \\
\hline 1-2 per week & 19 & $51 \%$ \\
\hline 3-5 per week & 5 & $13 \%$ \\
\hline 6-8 per week & 0 & $0 \%$ \\
\hline Other & 13 & $35 \%$ \\
\hline
\end{tabular}

It is interesting to note the number of children who are using app stores without the help of their parents. Figure 1 shows the proportion of children who download games with the help of a parent or individually.

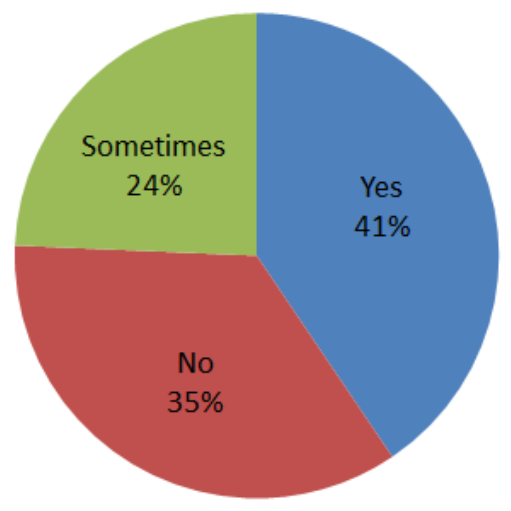

Figure 1: Q4: Proportion of children who get help from parents when using app stores

It is not known if this was just help with entering a user account password to download games as children were not asked any questions regarding passwords for ethical reasons. It is interesting that $35 \%$ of children claim to do this without any help and this raises issues about children's performance when navigating app stores independently and whether this could be improved.

Children were also asked about mobile phone game usage. Table 3 illustrates the frequency that children play the games they have downloaded.

Table 3: Q5: Frequency children play mobile phone games

\begin{tabular}{|l|l|l|}
\hline \multicolumn{1}{|c|}{ Frequency } & \multicolumn{1}{c|}{ No. } & \multicolumn{1}{c|}{ \% } \\
\hline Every day & 12 & $32 \%$ \\
\hline Every week & 18 & $49 \%$ \\
\hline every month & 5 & $14 \%$ \\
\hline never & 2 & $5 \%$ \\
\hline
\end{tabular}

The high number of respondents playing games weekly could indicate that there is some control over the child's access to mobile phone games. Which would most likely be the case if a child was only using the parents phone to access the games (as seen in Table 1). Although many manufacturers provide security settings that help avoid unwanted purchases from children (such as in-app purchases or premium games), these may not be enabled on parents/adults phones.

Children were also asked how they chose the games they downloaded (Q6). Table 4 illustrates the responses.

Table 4: Q6: How children choose games

\begin{tabular}{|l|l|l|}
\hline \multicolumn{1}{|c|}{ Statement } & Frequency & \% \\
\hline I read about it & 6 & $16 \%$ \\
\hline I just found it & 6 & $16 \%$ \\
\hline I have played it before & 7 & $19 \%$ \\
\hline My friend told me about it & 13 & $35 \%$ \\
\hline My mum and dad chose it & 3 & $8 \%$ \\
\hline Other & 2 & $5 \%$ \\
\hline
\end{tabular}

Over $50 \%$ of participants responded they choose games either by having played them before or on the recommendation of a friend. Only $8 \%$ of the children primarily play the games their parents choose for them. This suggests children both discuss mobile phone games amongst their peers and also have a desire to discover games of their own, or games aligned to their friends interests. This raises an interesting question as to whether children find application stores intuitive to use, as prior research has shown the categories used in some application stores are not currently intuitive to 
younger children as they are too abstract (Cassidy, Antani \& Read, 2013).

The final two survey questions explore children's views on this. Figure 2 illustrates how easy children felt it was to find the games they wanted on app stores.

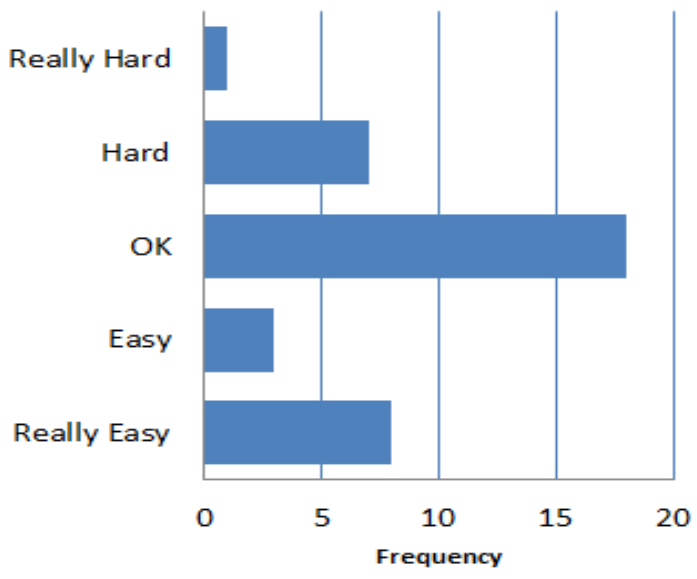

Figure 2: Q7: how easy children felt it was to find a chosen game on an app store

Only $30 \%$ of children who play games find it easy or really easy to find the games they want. With $22 \%$ finding it hard or really hard.

Normally when conducting research with children, especially with likert scale questions, it is often seen that children generally prefer not give a neutral answer and are often compelled to provide a positive answer (Read, 2008). As there are a large number of neutral answers, this suggests that children may feel that application stores could be improved.

\subsection{Opinions on Improvements}

The final question in the survey was an open ended question asking children about what aspects of app stores they felt could be improved. The answers were analysed and grouped into related categories based on the common themes of the answer given. Answers that could not sensibly fit into any of the five groupings produced were placed into an 'other' group. The categories and example responses are reproduced in the following subsections

\subsubsection{Search Related Responses}

8 Responses in total, typical responses were:

\footnotetext{
"Type in the first letter and all the games come up"

"When you put the name in it comes straight up"

"Type a single letter in and the games show up"
}

\subsubsection{Category Related Responses}

7 Responses in total, typical responses were:

"Put in a category about the type of game"

"Sections like girls/ boys and animals"

"Certain games under different folders"

\subsubsection{Help from Others}

4 Responses in total, typical responses were:

"Ask my mum"

"Make my parents or sister help me"

"People show you the game and tell you how to find it"

\subsubsection{Efficiency / Performance}

4 Responses in total, typical responses were:

"If it came up faster"

"If you didn't have to press two buttons at the same time"

"By all the games coming up straight away"

\subsubsection{No Improvements}

4 Responses in Total, typical responses were:

\author{
"Nothing" \\ "Don't know" \\ "Nothing"
}

\subsubsection{Other Suggestions}

7 Responses in Total, typical responses were:

"My favourite game on the front cover"

"If they put how many people play it"

"If you had a games app on your phone"

Categories that received the most responses were related to search and categorisation. It is already known that some categories in application stores do not make sense to children (Cassidy, Antani \& Read, 2013), which may explain why improvements to text search are also popular suggestions with children.

\section{DISCUSSION}

The results raise some interesting implications for app store developers. The survey suggests children are prolific users of mobile phone application stores. A proportion of children claim to use these stores independently and discuss games they have found with their friends. App stores offer many games for free, which is an attractive prospect for children who may tire of games easily and may not be allowed to spend frequently on new game purchases.

Supporting children in the design of app store interfaces could lead to improved usage by children who have their own views on how app stores could be improved. These views mainly centred around finding the games that they wanted. Categories that are less abstract and more in line with Piaget's research on child development (Piaget, 1973) could help children browse to games in application stores easier.

Categories that are more aligned to the characters in the game (for example an "Animals" category may help improve children's experience when finding games they want to download from the app 
store. A 'child friendly' app store interface could also help children find content that is suitable for them and help reduce the risk of downloading inappropriate applications. With many application store accounts linked to a particular profile on the users smartphone, and the introduction of child specific user profiles on some smartphone operating systems, presenting a personalised user interface and categorisation schema for application stores may not be such a challenge in the future.

\section{CONCLUSIONS AND FUTURE WORK}

The survey carried out was very short and had a very narrow scope with the aim of keeping children engaged with the questions in order to improve reliability. The scope of the survey was simply to establish whether children were using app stores and how they used them generally. Although it is known children are now users of mobile phones, the extent to which they used smart phones and in particular app stores was not previously known.

The survey could be extended to look at searching behaviour, spending habits and where and when children use app stores (e.g. To what extent do they download games to adults phones while out of the house with parents?).

This paper provides evidence that children are using application stores both on their own and on their parent's phones. It has shown that children often use application stores to find games without the help of their parents. The paper provides grounding for further research on providing 'child friendly' categories for games in app stores. Future research could include investigative studies into what categories make sense to children and empirical studies to find out what category schemas provide the best performance.

The paper indicates that children are not just users of mobile games, but also consumers. Many of whom claim to use application stores independently, finding games based on the recommendations of friends. This should be acknowledged by designers by providing both additional support to children in finding the games they want, and by providing extra restrictions to prevent children finding inappropriate content or accidentally incurring charges to a parents account.

\section{REFERENCES}

BBC (2013) iTunes refund after Bristol boy's $£ 1,700$ spending spree. Available at http://www.bbc.co.uk/news/uk-england-bristol$\underline{21629210}$ (Accessed: 13 June 2013).
Cassidy, B., Antani, D. S., \& Read, J. C. (2013) Using an open card sort with children to categorize games in a mobile phone application store. In Proceedings of the SIGCHI Conference on Human Factors in Computing Systems. Paris April 2013. New York: ACM, pp. 2287-2290.

Davie, R. Panting, C \& Charlton, T. (2004) Mobile phone ownership and usage among preadolescents. Telematics and Informatics, 21(4). pp 359-373.

Denney, N. W. \& Ziobrowski, M. (1972) Developmental Changes in Clustering Criteria. Journal of Experimental Child Psychology, 13

Druin, A., Cavallo, D., Fabian, C., Bederson, B., Revelle, G., Rogers, Y. \& Gray, J. (2011) The future of child-computer interaction. In PART 2, Proceedings of the 2011 annual conference extended abstracts on Human factors in computing systems (CHI EA'11). Vancouver May 2013, New York: ACM, pp. 693-696

Huchinson, H., Druin, A. \& Bederson, B. (2007) Supporting elementary age children's searching and browsing: Design and evaluation using the international children's digital library. Journal of the American Society for Information Science and Technology, 58(11), pp1618-1630.

Lewin, T. (2010). If your kids are awake, they're probably online. The New York Times, 20.

Mezei, G. Benyi, M \& Muller, A. (2007) Mobile phone ownership and use among school children in three Hungarian cities, Bioelectromagnetics, 28(4), pp 309-315.

Piaget, J. \& Inhelder, B. (1973) Memory and Intelligence. London: Routledge and Keegan.

Read, J. C. (2008) Validating the Fun Toolkit: an instrument for measuring children's opinions of technology. Cognition, Technology \& Work, 10(2), pp.119-128.

Rideout, V. J., Foehr, U. G., \& Roberts, D. F. (2010) Generation M2: Media in the Lives of 8-to 18-Year-Olds. Henry J. Kaiser Family Foundation.

Roberts, D, F. \& Foehr, U.G. (2008) Trends in media use. Children and Electronic Media. 18(1), pp11-38.

ThomsonReuters (2011) Class Action Complaint vs Apple Available at: http://newsandinsight.thomsonreuters.com/uploa dedFiles/National Litigation/Legal Materials/Co urt Filings/2011/04 April/AppleAppComplaint.pdf (Accessed: 13
June 2013) 